\title{
Disturbance Observer-Based Simple Nonlinearity Compensation for Matrix Converter Drives
}

\author{
Kyo-Beum Lee ${ }^{1}$ and Frede Blaabjerg ${ }^{2}$ \\ ${ }^{1}$ School of Electrical and Computer Engineering, Ajou University, Suwon 443-749, South Korea \\ ${ }^{2}$ Institute of Energy Technology, Aalborg University, 9100 Aalborg, Denmark \\ Correspondence should be addressed to Kyo-Beum Lee, kyl@ajou.ac.kr
}

Received 23 July 2008; Accepted 22 October 2008

Recommended by Henry S. H. Chung

This paper presents a new method to compensate the nonlinearity for matrix converter drives using disturbance observer. The nonlinearity of matrix converter drives such as commutation delay, turn-on and turn-off time of switching device, and on-state switching device voltage drop is modeled by disturbance observer and compensated. The proposed method does not need any additional hardware and offline experimental measurements. The proposed compensation method is applied for highperformance induction motor drives using a $3 \mathrm{~kW}$ matrix converter system without a speed sensor. Simulation and experimental results show that the proposed method using disturbance observer provides good compensating characteristics.

Copyright ( $\odot 2009$ K.-B. Lee and F. Blaabjerg. This is an open access article distributed under the Creative Commons Attribution License, which permits unrestricted use, distribution, and reproduction in any medium, provided the original work is properly cited.

\section{Introduction}

Induction motor drives fed by matrix converter have been developed for the last two decades [1]. The matrix converter drive has recently attracted the industry application, and the technical development has been further accelerated because of the increasing importance of power quality and energy efficiency issues [2].

Since the fundamental output voltage cannot be detected directly from the matrix converter output terminal in a matrix converter drive, the command voltage is usually used instead of the actual one. However, the commanded voltage does not agree with the actual fundamental output voltage due to nonlinear characteristic of the matrix converter, such as commutation delay, turn-on and turn-off time of switching device, and on-state switching device voltage drop. In order to compensate this problem, the authors have made an attempt to compensate the nonlinear matrix converter effects with current sign and offline manners [3]. However, it is difficult to determine the current sign when the phase currents are closed to zero. If the current sign is misjudged, the nonlinearity model of a matrix converter operates improperly. It is also difficult to compensate the nonlinearity effects perfectly by offline manners because the switching times and voltage drops of the power devices are varied with the operating conditions [4].

In this paper, a new online nonlinearity compensation method for matrix converter drives using a disturbance observer is proposed. Figure 1 shows the whole control block diagram of a sensorless vector-controlled matrix converter drive with disturbance observer-based nonlinearity compensation. The proposed method does not need any additional hardware and offline experimental measurements. The paper calculates the nonlinearity of matrix converter drives using disturbance observer, and the simple feed-forward control method applies to make the compensation voltages in order to compensate the nonlinear model of matrix converter drives (see Figure 1).

\section{Disturbance Observer-Based Nonlinearity Compensation}

2.1. Back-EMF Voltage Estimation. The back-EMF voltage equation for the stator of an induction motor in the stationary reference frame can be expressed as

$$
\mathbf{e}=\mathbf{v}_{s}-L_{l s} \frac{d}{d t} \mathbf{i}_{s}
$$




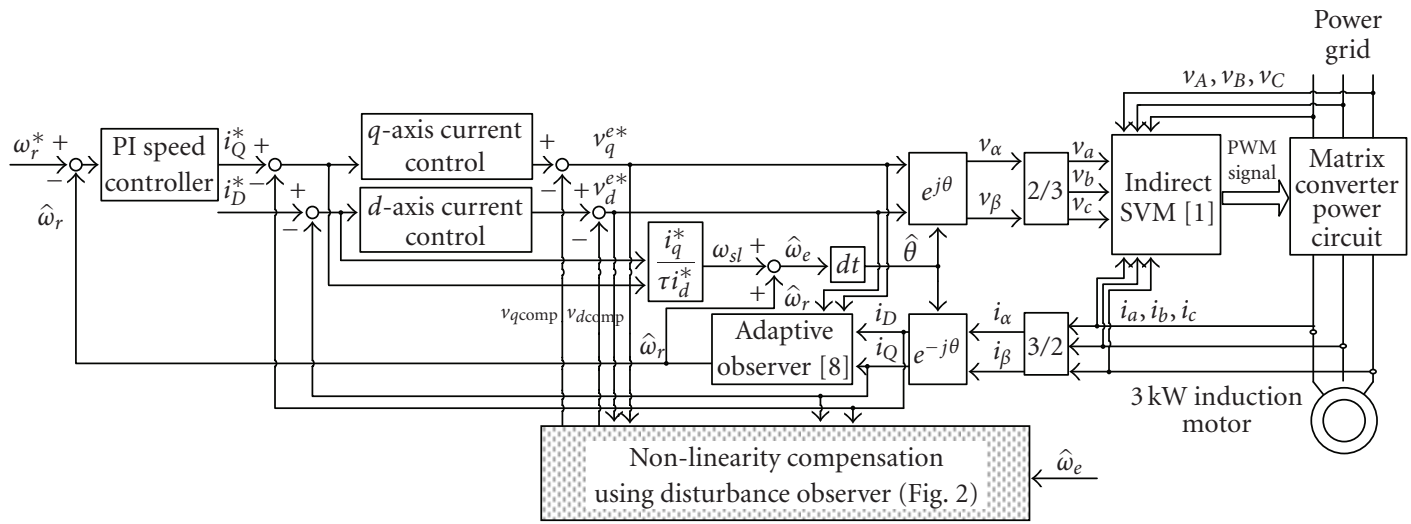

FIGURE 1: The proposed sensorless vector control for matrix converter drives.

If $\mathbf{v}_{s}^{*}$ is the desired applied voltage, (1) can be restated as

$$
\widehat{\mathbf{e}}=\mathbf{v}_{s}^{*}-L_{l s} \frac{d}{d t} \mathbf{i}_{s},
$$

where $\hat{\mathbf{e}}$ is the estimated back-EMF voltage.

Because of the nonlinearity of a matrix converter drive, the command voltage from the controller $\mathbf{v}_{s}^{*}$ is not the real applied voltage $\mathbf{v}_{s}$ that appears on the motor terminals.

From (1) and (2), the error equation for the back-EMF voltage can be written as

$$
\mathbf{e}-\hat{\mathbf{e}}=\mathbf{v}_{s}-\mathbf{v}_{s}^{*},
$$

where $\Delta \mathbf{v}$ is the voltage error $\mathbf{v}_{s}-\mathbf{v}_{s}^{*}$ by the nonlinearity of a matrix converter drive [5].

Using (1)-(3) can be rewritten as

$$
\mathbf{e}=\mathbf{v}_{s}^{*}-L_{l s} \frac{d}{d t} \mathbf{i}_{s}+\Delta \mathbf{v}
$$

In order to estimate the voltage error vector $\Delta \mathbf{v}$, especially important at low speed, this paper presents a method to compensate for the nonlinear matrix converter effects with a disturbance observer.

\subsection{Disturbance Observer-Based Nonlinearity Compensation.} The voltages due to the nonlinearity of matrix converter drives cause the matrix converter output voltage distortion, results in the phase current distortion and torque ripple. The disturbance voltages are a function of a commutation delay, turn-on and turn-off times of the switching devices, onstate switching device voltage drop, and a current polarity. However, the commutation delay, on-state voltage drop of the switching devices, and a current polarity are varying with the operating conditions. Since it is very difficult to measure the commutation delays and the on-state voltage drops, as well as to determine the current sign when the phase currents are closed to zero, it is not easy to compensate the nonlinearity of matrix converter drives in an offline manner. To alleviate these problems, a new online nonlinearity compensation method using disturbance observer is proposed. The proposed scheme is shown in

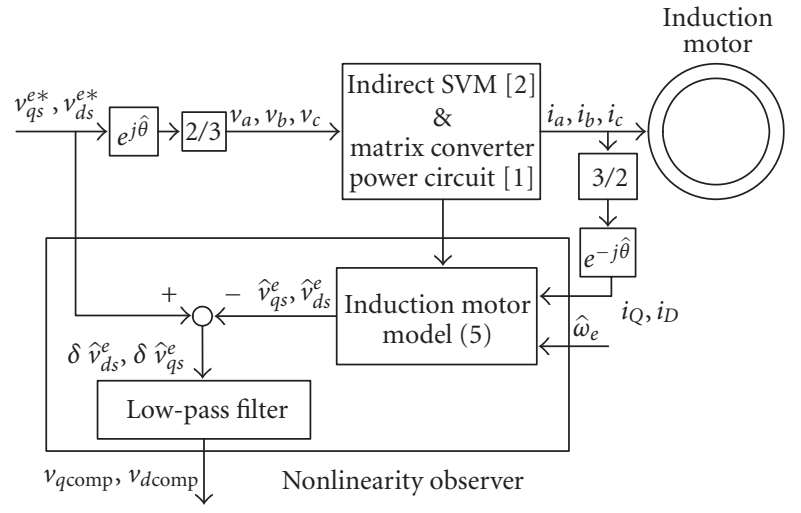

FIGURE 2: Block diagram of nonlinearity observer.

Figure 2, which consists of an inverse machine model and a simple first-order low-pass filter.

The estimated $d$ - and $q$-axis voltages can be written as

$$
\begin{aligned}
& \hat{v}_{d s}^{e}=R_{s} i_{d s}^{e}-\hat{\omega}_{e}\left(\lambda_{q m}^{e}+L_{l s} i_{q s}^{e}\right), \\
& v_{q s}^{s}=R_{s} i_{q s}^{s}+\widehat{\omega}_{e}\left(\lambda_{d m}^{e}+L_{l s} i_{d s}^{e}\right) .
\end{aligned}
$$

The disturbance observer estimates the nonlinearity distorted voltage $v_{\text {dis }}$ by using the inverse motor model $P_{n}^{-1}(s)$ as follows:

$$
\begin{aligned}
\delta & =u-P_{n}^{-1}(s)(y-\gamma) \\
& =\left(P^{-1}(s)-P_{n}^{-1}(s)\right) y+v_{\mathrm{dis}}+P_{n}^{-1}(s) \gamma \\
& \triangleq \Delta_{P}(s) y+v_{\mathrm{dis}}+P_{n}^{-1}(s) \gamma,
\end{aligned}
$$

where the outputs $y$ are currents, $P(s)$ is the real motor model, $P_{n}(s)$ is the nominal motor model, $v_{\text {dis }}$ is the total nonlinearity of a matrix converter drive, $\gamma$ is the measurement noise (currents and motor speed), and $\Delta_{p}(s)$ in the first term is the perturbation of the real model from the nominal model. Therefore, the nonlinearity observer estimates not only the nonlinearity of a matrix converter, but also the perturbation of the real model from the nominal model. 


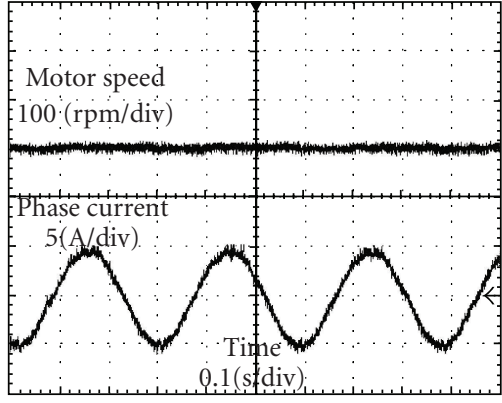

(a) With the proposed compensation

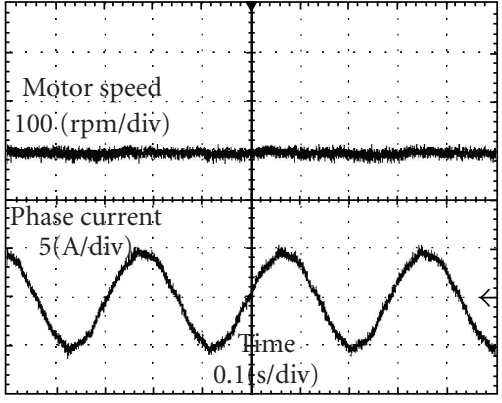

(b) Without compensation

FIGURE 3: Experimental result of current control at $100 \mathrm{rpm}$ (speed and phase current).

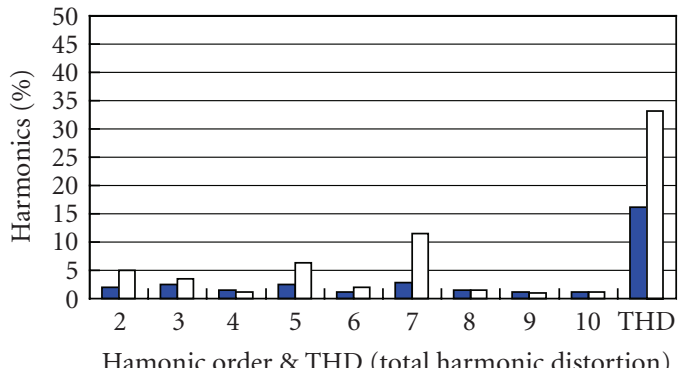

With compensation

Without compensation

FIgURE 4: Comparison of output current harmonics at $100 \mathrm{rpm}$.

Since the inverter nominal plant $P_{n}^{-1}(s)$ includes some derivatives, the disturbance observer estimates the disturbance $\Delta$ through a low-pass filter $Q(s)$ as follows:

$$
\Delta=Q(s) \delta .
$$

If the estimated disturbance $\delta$ is fed back as shown in Figure 2, the output signal can be described by the disturbance, the measurement noise, and the control input signal as follows:

$$
\begin{aligned}
y & =\frac{u-(1-Q(s)) d+Q(s) P_{n}^{-1}(s) \gamma}{Q(s) P_{n}^{-1}(s)+(1-Q(s)) P^{-1}(s)} \\
& =\frac{P_{n}(s)\{u-(1-Q(s)) d\}+Q(s) \gamma}{1+(1-Q(s)) \Delta_{P}(s) P_{n}(s)} .
\end{aligned}
$$

If conditions $(1-Q(s)) v_{\text {dis }} \approx 0,(1-Q(s)) \Delta_{P}(s) P_{n}(s) \approx 0$, and $Q(s) \gamma \approx 0$ are satisfied, the output signal $y$ can be obtained as in (9), in which it has no relation with the disturbance. As a result, the estimated disturbance is nearly close to the practical disturbance:

$$
y=P_{n}(s) u .
$$

$Q(s)$ must be determined according to the characteristics of the disturbance $d$ and the plant perturbation $\Delta_{P}(s)$, so that
$(1-Q(s)) v_{\text {dis }}$ and $(1-Q(s)) \Delta_{P}(s) P_{n}(s)$ fulfil a specification. Since plant perturbation $\Delta_{P}(s)$ affects the stability of control system, it is desirable to make $\Delta_{P}(s)$ small, which is realized by determining the nominal plant $P_{n}(s)$ close to the plant $P(s)$. On the other hand, since $Q(s)$ is the sensitivity to the sensor noise, $Q(s)$ must be determined, so that influence of the sensor noise does not become excessively large. Therefore, the bandwidth of the low-pass filter $Q(s)$ is limited by the bandwidth of the sensor noise $\gamma$.

\section{Experimental Results}

To confirm the validity of the proposed control algorithm, simulations and experiments are carried out. The low-speed operation is especially focused on the simulation and experiment. The hardware consists of a 3-phase, $380 \mathrm{~V}, 50 \mathrm{~Hz}, 4$ pole, $3 \mathrm{~kW}$-induction motor, and power circuit with a matrix converter. A dual controller system consisting of a 32-bit DSP (ADSP 21062) and a 16-bit microcontroller (80C167), in conjunction with a 12 -bit $\mathrm{A} / \mathrm{D}$ converter board is used to control the matrix converter-based induction motor drive [5]. Figure 3 shows the experimental results of the current control with and without the nonlinearity compensation in the low-speed region. The motor is operated at $100 \mathrm{rpm}$. It can be seen from Figure 4 that the 5th and 7th harmonic currents are reduced by $61 \%$ and $75 \%$ with the proposed compensation method using the disturbance observer.

\section{Conclusion}

In order to realize high-performance control of induction motor drives fed by matrix converter, a new online compensation method for a nonlinearity of matrix converter drives has been proposed in this paper. The proposed method using disturbance observer compensates the nonlinearity of a matrix converter drive such as commutation delay, turn-on and turn-off time of switching device, and an on-state switching device voltage drop in online manner. Experimental results show that the proposed compensation method can provide good compensation performance. 


\section{References}

[1] M. P. Kazmierkowski, F. Blaabjerg, and R. Krishnan, Control in Power Electronics: Selected Problems, Academic Press Series in Engineering, chapter 3, Academic Press, Boston, Mass, USA, 2002.

[2] C. Klumpner, P. Nielsen, I. Boldea, and F. Blaabjerg, "A new matrix converter motor (MCM) for industry applications," IEEE Transactions on Industrial Electronics, vol. 49, no. 2, pp. 325-335, 2002.

[3] K.-B. Lee and F. Blaabjerg, "A nonlinearity compensation method for a matrix converter drive," IEEE Power Electronics Letters, vol. 3, no. 1, pp. 19-23, 2005.

[4] K.-B. Lee, F. Blaabjerg, and T.-W. Yoon, "Speed-sensorless DTC-SVM for matrix converter drives with simple nonlinearity compensation," IEEE Transactions on Industry Applications, vol. 43, no. 6, pp. 1639-1649, 2007.

[5] P. Nielsen, F. Blaabjerg, and J. K. Pedersen, "New protection issues of a matrix converter: design considerations for adjustable-speed drives," IEEE Transactions on Industry Applications, vol. 35, no. 5, pp. 1150-1161, 1999. 

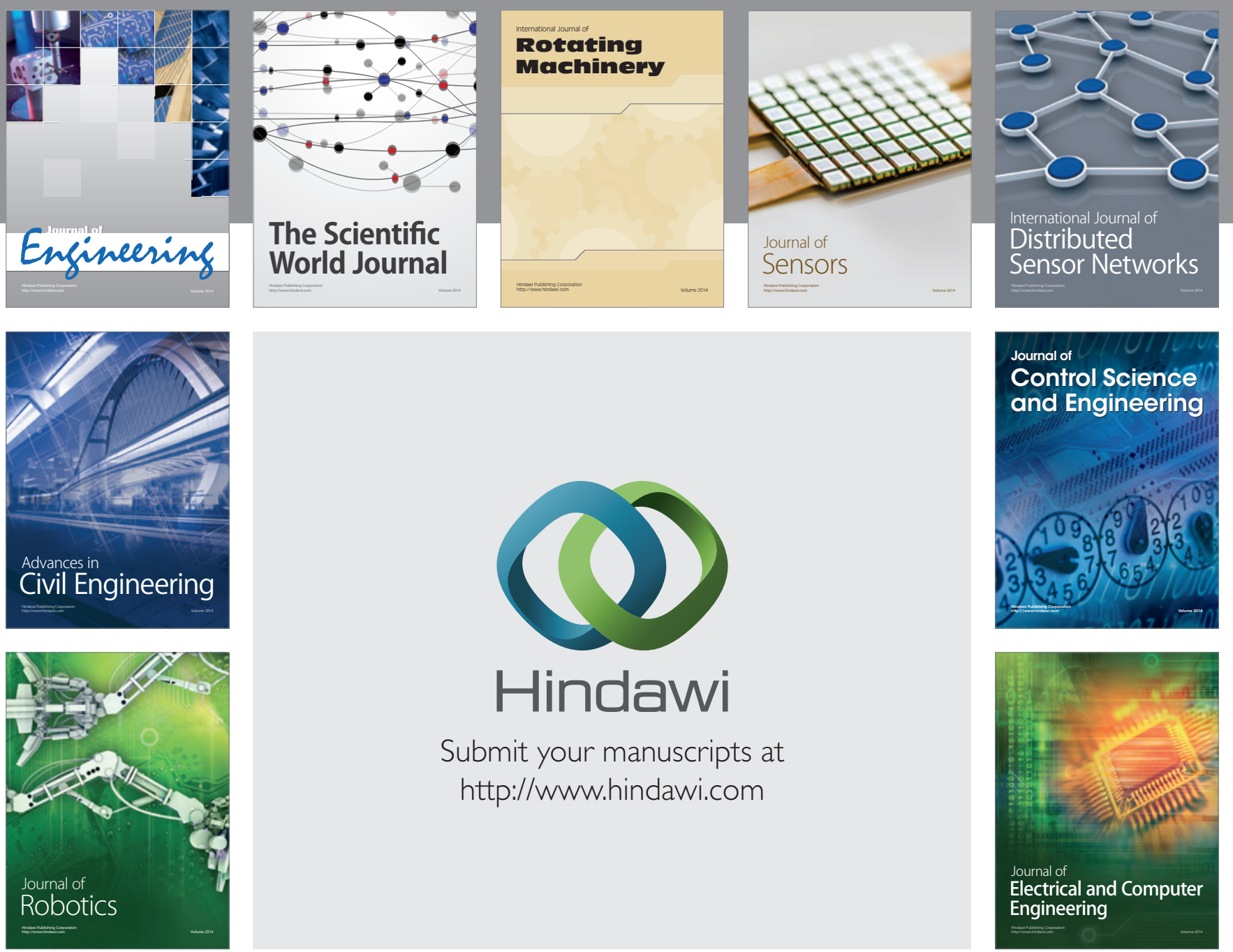

Submit your manuscripts at

http://www.hindawi.com
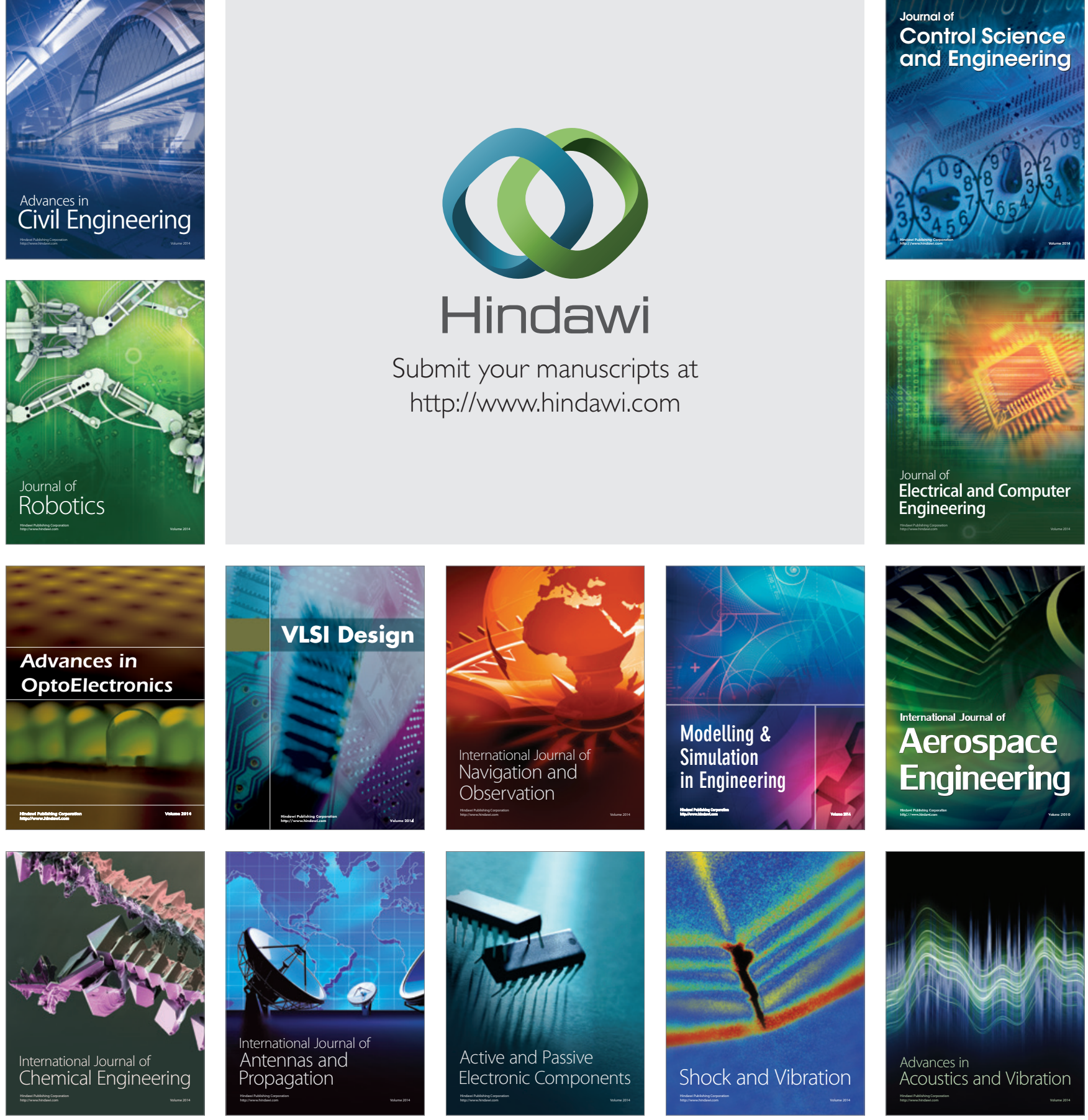